\title{
Right Diet: a television series to combat obesity among adolescents in Kuwait
}

This article was published in the following Dove Press journal:

Diabetes, Metabolic Syndrome and Obesity:Targets and Therapy

5 July 2012

Number of times this article has been viewed

\author{
Ahmad R Al-Haifi' \\ Mohammad A Al-Fayez' \\ Bader Al-Nashi' \\ Buthaina I Al-Athari' \\ Hiba Bawadi² \\ Abdulrahman $\bigcirc$ Musaiger ${ }^{3}$ \\ 'Department of Food and Nutrition, \\ College of Health Sciences, Showaikh, \\ Kuwait; ${ }^{2}$ Department of Nutrition and \\ Food Science, Jordan University of \\ Science and Technology, Irbid, Jordan; \\ ${ }^{3}$ Nutrition and Health Studies Unit, \\ University of Bahrain and Arab Center \\ for Nutrition, Kingdom of Bahrain
}

Background: Adolescent obesity is a growing public health problem in Kuwait. Reducing obesity can lower the risk of several chronic diseases. Fourteen obese adolescent boys volunteered to participate in a 6-month multidimensional television series on weight loss.

Methods: The adolescent boys were recruited through advertisements in schools. The program included counseling sessions, nutritional education, exercise, family support, peer group involvement, and incentives designed to motivate participants.

Results: The mean age of the boys was $15.6 \pm 0.8$ years. On average, subjects lost $10.6 \pm 8.9 \mathrm{~kg}$ in weight and gained $3.3 \pm 1.6 \mathrm{~cm}$ in height during the study period. The difference in mean body mass index at baseline and at 6 months following intervention was significant $(P<0.001)$ at $36.8 \pm 4.6$ and $32.0 \pm 5.4, \mathrm{~kg} / \mathrm{m}^{2}$ respectively. Participants ranked counseling as the most important component of the program, followed by family support and type of program.

Conclusion: This type of television series could be used as a model for future public health programs to prevent and control obesity among adolescents.

Keywords: diet, television, obesity, adolescents

\section{Introduction}

Kuwait, an Arab Gulf country, has one of the highest levels of adult overweight and obesity in the world, ranging between $70 \%$ and $80 \% .^{1}$ Among children and adolescents, obesity is one of the fastest growing health problems in this region. It was found that overweight and obesity among Kuwaiti adolescents has increased by $13 \%$ during 2004-2009. 2,3 This has profound public health implications in the context of chronic disease prevention and lifespan. ${ }^{4,5}$ In general, as among adults, the proportion of overweight and obesity among Kuwaiti adolescents (aged 10-19 years) is one of the highest worldwide, ranging from $42 \%$ to $45 \%$.

A relatively large body of fairly consistent evidence demonstrates that obesity in childhood and adolescence has adverse consequences on morbidity and mortality in adulthood. ${ }^{8-10}$ Fortunately, modest weight loss has been found to improve several chronic diseases, particularly heart disease, pulmonary disease, certain types of cancers, type 2 diabetes, psychological problems, and sleep apnea. ${ }^{11,12}$

A strategy to prevent obesity in Kuwait, especially among children and adolescents, is urgently needed. However, effective prevention and control strategies or direct interventional programs are lacking in Kuwait and in most developing countries. Although lifestyle intervention programs have been conducted in school settings in many countries, there has been no clear evidence of the efficacy of such intervention. Findings from lifestyle intervention programs in school settings have been limited Nutrition and Health Studies Unit.

University of Bahrain,

Arab Center for Nutrition,

PO Box 26923, Kingdom of Bahrain

Tel +97339625955

Fax +973 I734 6339

Email amusaiger@gmail.com
Diabetes, Metabolic Syndrome and Obesity: Targets and Therapy 20I 2:5 205-2I2

(C) 2012 Al-Haifi et al, publisher and licensee Dove Medical Press Ltd. This is an Open Access article which permits unrestricted noncommercial use, provided the original work is properly cited. 
by methodological concerns and have primarily focused on basic measures of obesity, such as body mass index. ${ }^{13,14}$ Most interventions did not reduce body mass index. However, it is known that physical activity can increase lean muscle mass and decrease fat mass, with no changes in body mass index. ${ }^{15}$ Findings from other studies have encouraged continuation of media campaigns targeted to changing food habits and physical activity patterns. ${ }^{16,17}$ However, a media campaign itself has little effect on self-awareness of weight status or weight loss behavior. ${ }^{18}$ Therefore, there is a need for innovative effective management and prevention to change the dietary and lifestyle habits of adolescents.

On the other hand, in response to the management of obesity, many reality television series about weight loss have been screened around the world, such as "The Biggest Loser,"19 "Losing it with Jillian", ${ }^{20}$ and "I used to be Fat."21 These television shows have the potential to inspire millions of viewers, especially adults, to move themselves off the couch and into the gymnasium, and perhaps cut back on fast foods and prepare healthier meals. Reality shows discuss health, diet, cooking and meal preparation, exercise, attitudes, motivation, the role of alternative therapies such as yoga or other forms of stress management, and other educational issues involved in obesity management. Such comprehensive changes in behavior would help to reduce the risk of some chronic diseases, such as diabetes, heart disease, and stroke. Some critics have argued that these weight loss reality television shows may encourage unhealthy practices in the name of rapid weight loss, inspired by visions of winning large sums of prize money. A further criticism of weight loss reality television shows, is that they are, in fact, far from "reality".

Although adult weight loss and fitness television programs have become very popular around the world, especially in the US, adolescent weight loss television shows have received little attention. In addition, given the need for effective interventions to prevent and control obesity among adolescents, we are unaware of any existing television programs that include comprehensive activities in their interventions, such as inclusion of parents. During adolescence, teenagers are becoming independent and self-determined enough to establish personal eating habits and lifestyle patterns. Therefore, given the problem of adolescent obesity in Kuwait, television programs could be a convenient tool to provide adolescents with a set of principles to modify their food habits, increase their physical activity, and remove some of the barriers related to obesity management. ${ }^{22}$
The aim of this paper is to highlight the Right Diet program, the first television series in Kuwait targeted to reducing $10 \%$ of initial body weight in obese adolescent boys over 6 months by encouraging them to: improve their eating habits; reduce their daily caloric consumption by 500 calories without requiring major changes in current food intake; increase their level of physical activity (expend 1500 calories/week on at least moderate activities); modify their behavior by dealing with the difficulties and emotions of being obese; and support their parents and families in understanding the importance of healthy weight and making healthier choices in relation to diet and physical activity. The impact of these strategies on adolescent boys (age 15-18 years) was measured to assess the extent to which strategic exposure was associated with improvements in awareness, intentions, and behaviors with respect to weight loss. The results of this study may help in determining the effects of the counselor, peer group, family, and others on weight management in adolescents.

\section{Materials and methods \\ Participants}

This was an interventional prospective study that included 14 obese male adolescents aged $15-18$ years. The participants were recruited through advertising in private and public schools. One boys school was selected randomly from each six governorates in Kuwait. The obese children and their parents were invited to an open discussion to explain the aim of the program and to attend a main meeting regarding this television series which was filmed in the College of Health Sciences three days later. The Right Diet television program was explained in detail to all adolescents who attended, as well as their parents. Written informed consent from parents of adolescents younger than 18 years was required at the time of the starting date of the study. The adolescents were informed that they were free to withdraw from the study at any time. The rationale for including only male adolescents was to avoid the impact of gender differences in body structure and function, ie, size, shape, composition, functional development, and hormonal changes. Another important factor was the cultural and social constraints on females, because most Kuwaiti families have restrictions on allowing their girls to be outdoors for long periods.

Apparently healthy obese boys aged 15-18 years were eligible for inclusion in this study. The International Obesity Task Force standard for age was used to identify obese adolescents. ${ }^{23}$ Those with chronic diseases, including heart disease, cancer, physical limitations, endocrine disorders, diabetes mellitus, and blood pressure $\geq 140 / 90 \mathrm{mmHg}$ 
were excluded from the study. This cutoff was used to allow more obese students to join the program, especially with the low rate of adolescents willing to participate in such a program.

Of 90 adolescents who responded to the advertisements and attended the meeting in the College of Health Sciences, only 19 fulfilled the inclusion criteria. Some adolescents were overweight but not obese, and therefore were excluded from the program. Five of the adolescents selected withdrew from the study because of travel obligations for their families and their commitments with summer school examinations, leaving a final sample of 14 adolescent participants.

\section{Right Diet television series staff}

In addition to the 14 obese adolescent participants and their parents, the television series required participation of other experts and technical support personnel. The following television and expert staff participated in the "reality" television obesity intervention series: a nutrition counselor who was available during each entire program, nutritionists, physicians, physical activity specialists, and psychologists. These people were invited to join episodes in the television program to discuss with the adolescents several approaches and factors encountered in their behavior which could reduce weight. Persons who succeeded in losing weight also participated in the television series to give their stories on how they managed to lose weight. Parents were regularly invited to give support to their adolescents.

\section{Intervention}

The intervention was based on six key strategies continued for a period of 6 months.

\section{Strategy I}

Strategy 1 determined the causes of obesity by identifying any underlying diseases (such as an endocrine disorder) that might be the cause of obesity and hinder any attempts to lose weight.

\section{Strategy 2}

Strategy 2 identified lifestyle components, such as food habits, physical activity patterns, and other behavior which may be contributing to obesity. All participants completed a questionnaire regarding their food habits and physical activity levels at the time of the starting date. Parents were also invited to complete a questionnaire related to their lifestyles and health practices.

\section{Strategy 3}

Strategy 3 determined the sources of excess calories and provided correction through nutrition education classes, weight loss diets, and personal advice. Weight loss diets were provided to the adolescents based on dietary guidelines and the dietary habits of the boys and their families. Daily diet plans were 400-500 calories lower than the usual diet of the participants. Diet plans were composed of $50 \%$ energy intake as carbohydrates, $20 \%$ as proteins, and $30 \%$ as fats.

\section{Strategy 4}

Strategy 4 involved modifying the behavior and raising the awareness of the participants. This strategy was achieved through four steps, ie, self-monitoring, making a commitment, setting realistic goals, and motivation.

\section{Strategy 5}

Strategy 5 encouraged support from parents and from others who may influence the eating habits and lifestyle of the adolescents, eg, brothers and experts.

\section{Strategy 6}

Strategy 6 comprised scheduled weekly meetings with the adolescents during the first 3 months, followed by monthly meetings until the end of the program.

\section{Setting}

This television series used two approaches, ie, advice to change dietary habits and physical activity patterns and group treatment by providing a low calorie diet to be followed. Interventional activities were divided into indoor and outdoor activities. Indoor activities included lectures held at the College of Health Sciences, and focused on dietary guidelines, healthy food choices, exchange food lists, physical activity, and behavioral modifications (eg, manage stress and stimulus control, monitoring of both eating habits and physical activity) in achieving weight loss and weight maintenance. Outdoor activities included visits to restaurants, coffee shops, supermarkets, and sport clubs, as well as walking on the beach. The aim of this intervention was to give a chance to participants to apply the knowledge they learned from the lectures. An exercise program was also included and aimed at expenditure of 1500-2000 calories per week for 6 months. To achieve this, participants were advised to undertake 60 minutes of moderate to vigorous exercise 3-5 times weekly. Examples of activities included walking, jogging, aerobic, stretch exercise, football, and basketball, as 
well as reduction in time spent watching television. All these activities were featured in the television series.

\section{Description of television episodes}

This "reality television" program consisted of 13 episodes. Each episode focused on a different aspect or topic associated with weight loss, and featured experts, athletes, and celebrities advising and discussing various aspects of weight management with the adolescents. The 13 topics featured were as follows:

- Episode 1: Health aspects and comorbidities of obesity.

- Episode 2: Factors determining obesity among adolescents.

- Episode 3: Designing a personal program for each participant and setting goals and objectives.

- Episode 4: Reducing calorie intake through modifying food habits.

- Episode 5: Reducing calorie intake in fast food meals.

- Episode 6: Reducing calorie intake in restaurant foods.

- Episode 7: Misconceptions related to weight loss.

- Episode 8: Role of physical activity in reducing weight.

- Episode 9: Type of physical activity needed to reduce weight.

- Episode 10: Side effects of fad diets, special drinks, and drugs to lose weight.

- Episode 11: Role of family in providing a supportive environment for weight loss.

- Episode 12: Managing weight loss during Ramadan (the fasting month).

- Episode 13: Final results of the weight loss program and advice and recommendations for preventing obesity.

The educational materials were designed by the Food and Nutrition Department, College of Health Sciences, Kuwait. The main counselor for this program was ARA. However, in each episode, supportive assistance from other nutritionists were obtained. The television series was filmed from March to August, 2010.

\section{Outcome measurements}

Height and weight were assessed at the start and end of the television series. Age-specific body mass index for boys were used to classify obesity at ages 15-18 years using the International Obesity Task Force standard. ${ }^{23}$ Body composition was not measured because of cultural and social factors which could have interfered with the flexibility of the program. During the program period, data were collected by questionnaire to determine which components of the program contributed to weight loss in participants.

\section{Data analysis}

Data analysis was performed using statistical software package SPSS version 17.0 (SPSS Inc, Chicago, IL). Descriptive statistics were performed to determine mean weight, height, body mass index, and weight loss. In addition, data were computed to determine feedback on the perceived effectiveness of program components. The paired $t$-test was used to compare data before and after the program. A $P$ value less than 0.05 was considered to be statistically significant.

\section{Results}

Table 1 shows the height, weight, and body mass index of the adolescents before and after the program. Before the program, the participants weighed $84-140 \mathrm{~kg}$. Approximately $75 \%$ of the participants had a body mass index greater than $33 \mathrm{~kg} / \mathrm{m}^{2}$ The average weight loss for all participants during the 6-month program was $10.6 \pm 8.9 \mathrm{~kg}(P=0.001)$. However, the participants gained $3.3 \pm 1.6 \mathrm{~cm}$ in height $(P<0.001)$. Mean body mass index at baseline and at 6 months following intervention was $36.8 \pm 4.6 \mathrm{~kg} / \mathrm{m}^{2}$ and $32.0 \pm 5.4 \mathrm{~kg} / \mathrm{m}^{2}$, respectively $(P<0.001)$. Participant 5 had the greatest weight loss at $26 \mathrm{~kg}$ and participant 6 had a weight gain of $2 \mathrm{~kg}$.

Table 2 shows the components of the television weight loss series and the perceived effects on participant's weight loss during the 6-month period of the study. The counselor was perceived by the participants as being the most important, with $85.7 \%$ reported that the counselor's influence was "very strong". Family support and type of program were ranked next highest in influence (64.3\% for each). Incentives and activities of the program were ranked least important in influencing the outcome.

\section{Discussion}

This study describes the first reality-based television series focusing on obesity prevention in Kuwaiti adolescents. The Right Diet television series provided direct easy access to highly personalized feedback on the weight, diet, physical activity, and health of participating adolescents. This encouraged and enabled participants to monitor themselves, and make rational judgments regarding the competing claims of fad diets. The findings show that the 13 episodes resulted in a $10 \%$ reduction in body weight in most participants during the 6-month study period.

On average, participants lost $10.6 \mathrm{~kg}$ and reduced their body mass index by $4.8 \mathrm{~kg} / \mathrm{m} .^{2}$ However, it is worth mentioning that gain in height was a confounding factor for reduction of body mass index in the participants. The weight loss achieved was largely due to the fact that the program 
Table I Height, weight, and body mass index of participants before and after the program

\begin{tabular}{|c|c|c|c|c|c|c|}
\hline \multirow[t]{2}{*}{ Participant } & \multicolumn{3}{|c|}{ Before program } & \multicolumn{3}{|c|}{ After program } \\
\hline & Height (cm) & Weight (kg) & BMI & Height (cm) & Weight (kg) & BMI \\
\hline I & 163 & 88 & 33.1 & 166 & 71 & 25.8 \\
\hline 2 & 175 & 130 & 42.4 & 177 & 110 & 35.1 \\
\hline 3 & 159 & 113 & 44.7 & 159 & 114 & 45.1 \\
\hline 4 & 164 & 95 & 35.3 & 169 & 91 & 31.9 \\
\hline 5 & 177 & 105 & 33.5 & 180 & 79 & 24.4 \\
\hline 6 & 169 & 106 & 37.1 & 173 & 108 & 36.1 \\
\hline 7 & 160 & 84 & 32.8 & 163 & 77 & 29.0 \\
\hline 8 & 164 & 91 & 33.8 & 171 & 85 & 29.1 \\
\hline 9 & 183 & 120 & 35.8 & 185 & 113 & 33.0 \\
\hline 10 & 170 & 116 & 40.1 & 174 & 107 & 35.3 \\
\hline 11 & 182 & 140 & 42.3 & 184 & 120 & 35.4 \\
\hline 12 & 178 & 94 & 29.7 & 182 & 87 & 26.3 \\
\hline 13 & $17 \mid$ & 123 & 42.1 & 175 & 100 & 32.7 \\
\hline 14 & 165 & 90 & 33.1 & 168 & 84 & 29.8 \\
\hline Total $($ mean $\pm S D)$ & $170.0 \pm 7.9$ & $106.8 \pm 17.3$ & $36.8 \pm 4.6$ & $173.3 \pm 7.9$ & $96.1 \pm 16.0$ & $32.0 \pm 5.4$ \\
\hline
\end{tabular}

Abbreviations: BMI, body mass index; SD, standard deviation.

used several strategies for weight reduction, such as family and peer influence, a physical activity program, counseling on dietary habits, and continuous follow-up for 6 months. Although the participants in this study were obese, by the end of the television program, 12 of them had lost enough weight to move from the obese category to the overweight category. Only two participants did not lose weight, and this was because they had previously followed fad diets which led to failure. Although adolescence is a critical time for intervention to control obesity and its associated health problems, the findings of this study suggest that a television weight loss program concept could be effective and important in guiding parents and adolescents to set appropriate achievable and sustainable weight loss goals.

In general, we can assume that this television series provided a safe, enjoyable, and social environment which may have contributed to weight reduction in the participants.
In addition, the program was flexible and did not require participants to stay in a camp, as with other reality television shows focusing on weight loss. These shows have been criticized for motivating participants to win prizes rather than to achieve a healthy weight. Accordingly, the results achieved in these weight loss reality television shows are arguably not representative of reality at all. Another criticism is that short-term weight loss will inevitably result in slowing of metabolism, leading to rapid uncontrollable weight gain in coming years. ${ }^{24}$

Weight loss by each participant in the current television series was achieved by a change in lifestyle (ie, dietary habits and physical activity) and included selection of activities and a dietary regimen. This television series used a number of techniques to achieve the desired outcomes, including modification of dietary habits, increasing physical activity, counseling, family involvement, as well as peer and other

Table 2 Effect of components of television series as perceived by adolescents

\begin{tabular}{|c|c|c|c|c|c|c|}
\hline Factor & $\begin{array}{l}\text { Very strong } \\
\text { (n) }\end{array}$ & $\begin{array}{l}\text { Strong } \\
\text { (n) }\end{array}$ & $\begin{array}{l}\text { Fairly strong } \\
\text { (n) }\end{array}$ & $\begin{array}{l}\text { Not fairly strong } \\
\text { (n) }\end{array}$ & $\begin{array}{l}\text { Not strong } \\
\text { (n) }\end{array}$ & $\begin{array}{l}\text { Not strong at all } \\
\text { (n) }\end{array}$ \\
\hline \multirow[t]{2}{*}{ Counsellor } & $85.7 \%$ & $7.1 \%$ & $7.1 \%$ & 0 & 0 & 0 \\
\hline & $(12)$ & (I) & (I) & & & \\
\hline \multirow[t]{2}{*}{ Family support } & $64.3 \%$ & $14.3 \%$ & $14.3 \%$ & $7.1 \%$ & 0 & 0 \\
\hline & (9) & $(2)$ & $(2)$ & (I) & & \\
\hline \multirow{2}{*}{$\begin{array}{l}\text { Type of program (education, } \\
\text { diet, and physical activity) }\end{array}$} & $64.3 \%$ & $14.3 \%$ & $7.1 \%$ & $14.3 \%$ & 0 & 0 \\
\hline & $(9)$ & $(2)$ & (I) & $(2)$ & & \\
\hline \multirow[t]{2}{*}{ Peer group } & $50.0 \%$ & $14.3 \%$ & $7.1 \%$ & $7.1 \%$ & $14.3 \%$ & $7.1 \%$ \\
\hline & $(7)$ & $(2)$ & (I) & (I) & $(2)$ & (I) \\
\hline Effect of television series & $42.9 \%$ & $14.3 \%$ & 0 & $7.1 \%$ & $21.4 \%$ & $14.3 \%$ \\
\hline on participants & $(6)$ & $(2)$ & & (I) & (3) & $(2)$ \\
\hline Incentives and activities & $21.4 \%$ & $7.1 \%$ & $21.4 \%$ & $14.3 \%$ & $14.3 \%$ & $21.4 \%$ \\
\hline of television series & (3) & (I) & (3) & $(2)$ & $(2)$ & (3) \\
\hline
\end{tabular}


psychosocial support services. Because this study was a multicomponent television series, it was not possible to identify the most effective interventions. The success of the participants in achieving and maintaining a negative energy balance may be highly dependent on nonspecific factors, such as the social environment of the television program, including the counselor, family support, and peer group. Such factors may assist in weight loss.

Counseling and follow-up were used to advise participants and educate them on safe and effective weight loss strategies and to guide them away from fad diets. ${ }^{25}$ In this study, the participants confirmed the importance of counseling as the most important factor in successful weight loss $(85.7 \%)$. As in another study, ${ }^{26}$ all participants at the beginning of the television series wanted intensive weight loss treatment as soon as possible. In fact, some participants reported disappointment at the beginning and others lost weight but later experienced no more weight reduction; however, the follow-up counseling helped the participants to control their weight successfully.

Many factors can influence the decision to counsel on weight loss. One common factor is the clinician's perception of the patient's receptiveness to suggestions. ${ }^{27}$ Lack of patient motivation is often cited by health care providers as a barrier to change. ${ }^{28}$ However, a health care provider's perception of motivation is not necessarily equivalent to the patient's self-reported motivation level. ${ }^{29}$ This discrepancy can negatively affect communication. Nevertheless, counseling by weight loss professionals and physicians provides insufficient guidance on weight management strategies, possibly because of inadequate skills and confidence on the part of the counsellor. ${ }^{30}$ Therefore, weight loss counseling by dieticians and physicians should have a significant effect on the patient's understanding and motivation for weight loss. In addition, the results of the current study suggests that it is important for weight loss professionals to spend a few minutes evaluating a teenager's readiness to change, setting appropriate weight loss goals, and providing information about how to modify dietary patterns. The teenager's current and past levels of physical activity should also be assessed, as well as any barriers to physical activity.

Parents play a fundamental role in the development of their teenager's food preferences and energy intake, and this includes their own eating behavior and motivation. ${ }^{31}$ Therefore, parents can create an environment for children and adolescents that may foster development of healthy eating behavior and maintenance of an appropriate weight, or may promote overweight and disordered eating. In this study, the role of parents, especially mothers, was viewed by the participants as the second most important determinant of weight loss after the counselor. Mothers in particular influence teenage eating behavior because they spend considerably more time than fathers in direct interaction with their teenagers in familial situations. The findings of our study and those of previous researchers ${ }^{31,32}$ suggest that effective prevention programs must focus on providing anticipatory guidance for parenting to foster patterns of preference and food selection in adolescents more consistent with healthy diets and also promote the ability of teenagers to self-regulate their intake of food. Guidance for parents should include information on how teenagers form their eating behaviors in the family context. Practical advice for parents should include how to foster teenager's preferences for healthy foods and how to promote acceptance of new healthy foods by adolescents. Parents need to understand the consequences of coercive feeding practices and be given alternatives to restricting food and pressuring teenagers to eat. Providing parents with easy-to-use information regarding appropriate portion sizes for adolescents is also essential.

On the other hand, individual lifestyle choices may also be directly influenced by peer behavior. This study confirms that peer support to modify eating behavior is also important in weight reduction strategies. A number of observational studies have investigated adolescent social networks and documented a positive correlation between an adolescent's weight and the average weight of their peers. ${ }^{33-35}$ This is particularly true in Kuwait, where friends meet at restaurants two or three times a week. Further, when regular exercise and sport become more popular in an individual's social network, the chances that the individual will engage in these activities increases, perhaps because of interest stimulated by peer involvement in this activity or social pressure to conform to group norms.

The main limitations of this study are its small number of participants and the lack of a control group or a randomly selected group of participants from a population-based sample as a comparator. However, a control group was difficult to include in this study for a number of social and cultural reasons. A long intervention program of this nature is unusual in Arab countries. Another important factor is that we did not include information on changes in energy intake, physical activity, and lifestyle. The adolescents who volunteered to participate in this television series may be different from those normally seen in public and private health clinics. Thus, selection bias remains a problem that must be resolved before one can generalize these results 
to the broader population. Despite these limitations, the benefits of this television series represent a valuable practical educational option for obese adolescents. In this study, encouraging progress was made in several areas, including diet, physical activity, behavior, and increased awareness of the problem of adolescent obesity.

In conclusion, using media tools such as a television series can be an effective strategy to promote healthy weight. The findings of this study are consistent with other studies utilizing various media as components of weight loss programs for children and adolescents. ${ }^{36}$ Other mediabased studies have focused on promoting healthy eating choices and increasing physical activity. ${ }^{17,37}$ Therefore, the government should encourage the media to promote healthy eating and physical activity. This study also indicates that parental involvement is key to the success of obesity prevention programs and may be a better method for improving a teenager's diet than attempts at dietary control. In addition, personalization of the diet and exercise regime was important in this television series. With the dramatically increasing prevalence of obesity among adolescents and its associated impact on health and longevity, there is an urgent need for specific media programs at the nationwide level to combat obesity among adolescents.

\section{Disclosure}

The authors report no conflicts of interest in this work.

\section{References}

1. World Health Organization. The World Health Organization warns of the rising threat of heart disease and stroke as overweight and obesity rapidly increase, 2011. Available at: http://www.who.int/mediacentre/ news/releases/2005/pr44/en/. Accessed May 22, 2012.

2. Al-Isa AN. Body mass index, overweight and obesity among Kuwaiti intermediate school adolescents aged 10-14 years. Eur J Clin Nutr. 2004;58:1273-1277.

3. El-Bayoumy I, Shady I, Lotfy H. Prevalence of obesity among adolescents (10 to 14 years) in Kuwait. Asia Pac J Public Health. 2009;21: $153-159$.

4. Lobstein T, Baur L, Uauy R. Obesity in children and young people: a crisis in public health. Obes Rev. 2004;5 Suppl 1:4-104.

5. Graf C, Koch B, Kretschmann-Kandel E, et al. Correlation between BMI, leisure habits and motor abilities in childhood (CHILT-Project). Int J Obes Relat Metab Disord. 2004;28:22-26.

6. Kuwait Ministry of Health. Kuwait Nutrition Surveillance (2001-2004). Food and Nutrition Administration. Kuwait City, Kuwait: Kuwait Ministry of Health; 2004.

7. Jackson RT, Rashed M, Al-Hamad N, Hwalla N, Al-Somaie M. Comparison of BMI-for-age in adolescent girls in 3 countries of the Eastern Mediterranean Region. East Mediterr Health J. 2007;13:430-440.

8. Freedman DS. Relation of body mass index and skinfold thicknesses to cardiovascular disease risk factors in children: the Bogalusa Heart Study. Am J Clin Nutr. 2009;90:210-216.

9. Franks PW. Childhood obesity, other cardiovascular risk factors, and premature death. N Engl J Med. 2010;362:485-493.
10. Reilly JJ, Kelly J. Long-term impact of overweight and obesity in childhood and adolescence on morbidity and premature mortality in adulthood: systematic review. Int $J$ Obes (Lond). 2011;35: 891-898.

11. McTigue KM, Harris R, Hemphill B, et al. Screening and interventions for obesity in adults: summary of the evidence for the US Preventive Services Task Force. Ann Intern Med. 2003;139:933-949.

12. Haslam DW, James WP. Obesity. Lancet. 2005;366:1197-1209.

13. Kropski JA, Keckley PH, Jensen GL. School-based obesity prevention programs: an evidence-based review. Obesity (Silver Spring). 2008; 16:1009-1018.

14. Flattum C, Friend S, Story M, Neumark-Sztainer D. Evaluation of an individualized counseling approach as part of a multicomponent schoolbased program to prevent weight-related problems among adolescent girls. J Am Diet Assoc. 2011;111:1218-1223.

15. Harris KC. Effect of school-based physical activity interventions on body mass index in children: a meta-analysis. CMAJ. 2009;180:719-726.

16. Flodmark CE, Lissau I, Moreno LA, Pietrobelli A, Widhalm K. New insights into the field of children and adolescents' obesity: the European perspective. Int J Obes Relat Metab Disord. 2004;28:1189-1196.

17. Beaudoin CE, Fernandez C, Wall JL, Farley TA. Promoting healthy eating and physical activity short-term effects of a mass media campaign. Am J Prev Med. 2007;32:217-223.

18. Morley B, Wakefield M, Dunlop S, Hill D. Impact of a mass media campaign linking abdominal obesity and cancer: a natural exposure evaluation. Health Educ Res. 2009;24:1069-1079.

19. National Broadcasting Commission. The biggest loser. Available at: http://www.nbc.com/the-biggest-loser/. Accessed May 22, 2012.

20. Michaels J. Losing it with Jillian. Available at: http://www. jillianmichaels.com/losing-it.aspx. Accessed May 22, 2012.

21. Music Television. I Used to Be Fat: Available at: http://www.mtv.com/ shows/i_used_to_be_fat/series.jhtml. Accessed May 22, 2012.

22. Caroli M, Argentieri L, Cardone M, Masi A. Role of television in childhood obesity prevention. Int J Obes Relat Metab Disord. 2004;28: S104-S108.

23. Cole TJ, Bellizzi MC, Flegal KM, Dietz WH. Establishing a standard definition for child overweight and obesity worldwide: international survey. BMJ. 2000;330:1240-1243.

24. Maclean PS, Bergouignan A, Cornier MA, Jackman MR. Biology's response to dieting: the impetus for weight regain. Am J Physiol Regul Integr Comp Physiol. 2011;301:R581-R600.

25. Galuska DA, Will JC, Serdula MK, Ford ES. Are health care professionals advising obese patients to lose weight? JAMA. 1999;282: 1576-1778.

26. Potter MB, Vu JD, Croughan-Minihane M. Weight management: what patients want from their primary care physicians. J Fam Pract. 2001;50:513-518.

27. Sussman AL, Williams RL, Leverence R, Gloyd PW Jr, Crabtree BF. The art and complexity of primary care clinicians' preventive counseling decisions: obesity as a case study. Ann Fam Med. 2006;4:327-333.

28. Jallinoja P, Absetz P, Kuronen R. The dilemma of patient responsibility for lifestyle change: perceptions among primary care physicians and nurses. Scand J Prim Health Care. 2007;25:244-249.

29. Befort CA, Greiner KA, Hall S. Weight-related perceptions among patients and physicians: how well do physicians judge patients' motivation to lose weight? J Gen Intern Med. 2006;21:1086-1090.

30. Huang J, Yu H, Marin E, Brock S, Carden D, Davis T. Physicians' weight loss counseling in two public hospital primary care clinics. Acad Med. 2004;79:156-161.

31. Scaglioni S, Salvioni M, Galimberti C. Influence of parental attitudes in the development of children eating behaviour. Br J Nutr. 2008; 99 Suppl 1:S22-S25.

32. Birch LL, Davison KK. Family environmental factors influencing the developing behavioral controls of food intake and childhood overweight. Pediatr Clin North Am. 2001;48:893-907.

33. Trogdon JG, Nonnemaker J, Pais J. Peer effects in adolescent overweight. J Health Econ. 2008;27:1388-1399. 
34. Halliday TJ, Kwak S. Identifying endogenous peer effects in the spread of obesity. Econ Hum Biol. 2009;7:181-190.

35. Ali MM, Amialchuk A, Renna F. Social network and weight misperceptions among adolescents. South Econ J. 2011;77:827-842. http://ssrn. com/abstract $=1782786$

36. Bauman AE, Bellew B, Owen N, Vita P. Impact of an Australian mass media campaign targeting physical activity in 1998. Am J Prev Med. 2001;21:41-47.
37. Price SM, Huhman M, Potter LD. Influencing the parents of children aged 9-13 years: findings from the VERB campaign. Am J Prev Med. 2008;34(6 Suppl):S267-S274.

38. Briggs M, Fleischhacker S, Mueller CG. American Dietetic Association; School Nutrition Association; Society for Nutrition Education. Position of the American Dietetic Association, School Nutrition Association, and Society for Nutrition Education: comprehensive school nutrition services. J Nutr Educ Behav. 2010;42:360-371.

\section{Publish your work in this journal}

Diabetes, Metabolic Syndrome and Obesity: Targets and Therapy is an international, peer-reviewed open-access journal committed to the rapid publication of the latest laboratory and clinical findings in the fields of diabetes, metabolic syndrome and obesity research. Original research, review, case reports, hypothesis formation, expert opinion and commentaries are all considered for publication. The manuscript management system is completely online and includes a very quick and fair peer-review system, which is all easy to use. Visit http://www.dovepress.com/testimonials.php to read real quotes from published authors.

Submit your manuscript here: http://www.dovepress.com/diabetes-metabolic-syndrome-and-obesity-targets-and-therapy-journal 